\title{
Design and Research on the Information Acquisition of Ginseng Ecological Factors Based on Internet Plus
}

\author{
Hongwei Zhu \\ Jilin Agricultural Science and Technology University, Jilin City, Jilin Province, 132101, China
}

Keywords: Internet plus; ecological factors; ginseng; information acquisition

\begin{abstract}
Ginseng is a kind of traditional medicines in China, and can nourish and build up the body. Due to the wild resources are scarce, ginseng has been classified as a category of protected herbs by the list of key protection of wild medicinal herbs and animals. In addition, the ginseng has a high requirement of ecological environments, so a blind planting and expansion not only make an unstable quality of ginseng, but also enhance great risks to farmers. Based on the "Internet plus" and the data analysis principle, this paper developed a information acquisition and control system for the whole growth period of ginseng so as to obtain ecological factors in time, and then several approaches were utilized to control the ecological factors to improve the cultivation precision and productions.
\end{abstract}

\section{Introduction}

The ginseng is the king of herbs and plays important roles in the traditional Chinese medicine industry. Modern medical research and clinical practice have proved that ginseng has a good therapeutic effect on central nervous system, cardiovascular system, digestive system, endocrine system and diseases of reproductive system. Due to reduction of the wild resource, the artificial planting of ginseng began in China, and was introduced into Korea and Japan in fifteenth Century. The former Soviet Union started artificial cultivation in early twentieth Century. At present, Northeast Asian countries have their own ginseng planting industry. Ecological factors are environmental elements that have direct or indirect impacts on biological, growth, development, reproduction, behavior and distribution, such as temperature, humidity, water content, oxygen, carbon dioxide and so on. The ginseng is a kind of cold, moist and shade resistant herb. It is afraid of water accumulation and drought resistance, which means the ginseng is more stringent on the growth environment.

\section{Situation of Information Collection of Ginseng Ecological Factors}

The planting and information technology of ginseng have been studied by many agriculture experts in recent years. The main problems are described as below.

At first, most of the information and control systems introduced in China re overcharged, and these systems designed and developed by ourselves lack the corresponding optimization, most of them still utilize the single factor method to regulate the ecological factors. However, the impacts of several ecological factors on the growth of ginseng are associated with each other, such as light, temperature, humidity, concentration of $\mathrm{CO} 2$ and so on. Besides, the temporal and spatial alternations of ecological factors are quite complex. When changing a certain ecological factor, other ecological factors would change to an unsuitable level.

Secondly, most of the ginseng management still rely on manual, which leads to that massive real-time information acquisition can not be done in time. It is unsuitable for modern intensive intelligent production due to consuming lots of energy and material resources. Furthermore, the information acquisition and control systems are quite limited due to the vast majority of horticultural facilities are too simple. Even though in normal weather, most plastic greenhouses can be controlled only by ventilation and shelter. When confronting with rain and snow, the greenhouse would face insufficient light and heat, leading to unsuitable environment for ginseng growth. 


\section{Profile of Internet Plus}

"Internet plus" refers to a set of information technology (including mobile Internet, cloud computing, big data technology and etc.) in economic activities, which is similar to Information Superhighway and Industry 4.0. "Internet plus” was proposed by China’s prime minister Li Keqiang in his Government Work Report on March 5, 2015 so as to keep pace with the Information Trend. It is a new economic model, using innovative achievements based on Internet technologies, to integrate all aspects in the economic society, enhance the development and competitiveness of real economy and form a new situation of economic.

Based on the above situation and new opportunities, this paper utilized "Internet plus" and the data analysis principle to design and research the information acquisition system of ginseng ecological factors. The main works are described as below. (1) A set of greenhouse cultivation system for the whole growth control of ginseng is developed to realize the supervision of the ginseng growth. (2) Based on computer science and Internet plus technology, such as Internet of thing, wireless communication, sensor / actuator, and the embedded system technology, the information collection of ecological factors can be realized. (3) Through Android application and development, an APP is designed to achieve the remote access of hardware and the remote monitoring.

\section{General Planning}

The information collection and control system can be divided into three aspects, respectively are the indoor, the outdoor and the cloud, which could be shown in Figure 1.

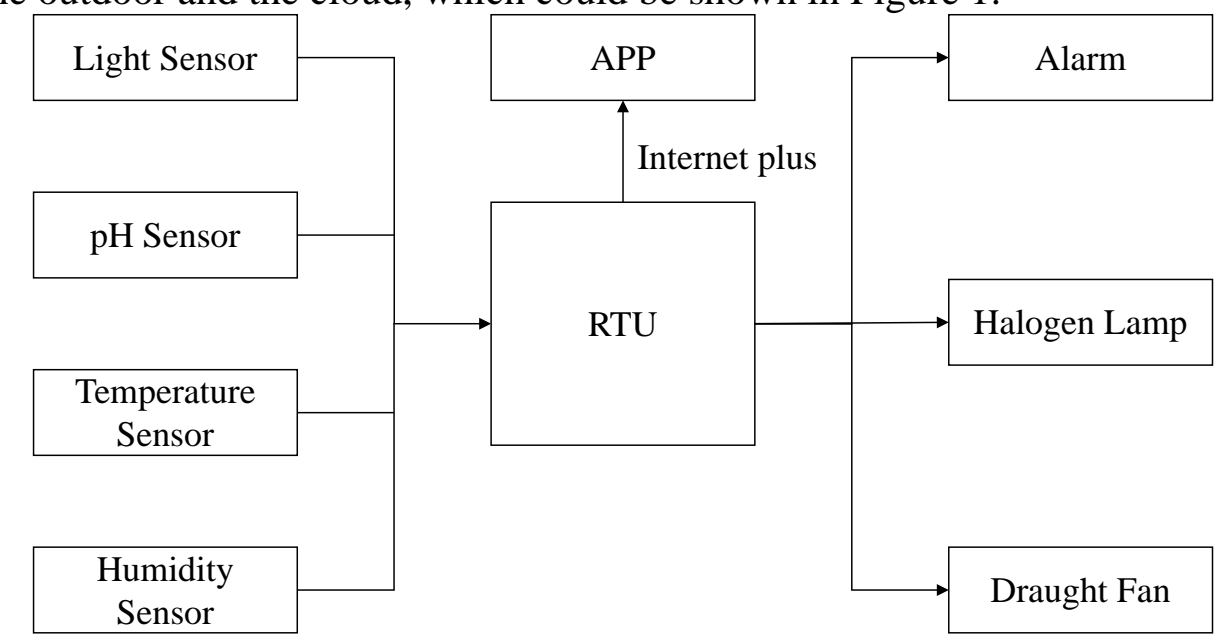

Figure 1 The profile of information collection and control system

There are a number of sensors, actuators and network equipment indoor. The sensors include the light sensor, the $\mathrm{CO} 2$ sensor, the temperature sensor, humidity sensor and $\mathrm{pH}$ sensor. The actuators include the alarm, the draught fan and the halogen lamp. All kinds of sensors and actuators are connected with RTU (Remote Transport Unit) through line connection. In addition, other equipment, such as supervision cameras, PC are connected with RTU through Internet.

There are an APP out door, which is connected with RTU through wireless Internet. Therefore, the remote monitoring, information collection, automatic control and other functions could be realized using this APP based on "Internet plus” technology.

The cloud is adopted to operate and restore massive data of ecological factors. Besides, the optimization of ecological factors could be obtained through remote mathematical models.

\section{Case Study}

\subsection{The cultivation of ginseng}

The case study is conducted in Heilongjiang Province. The cultivation is conducted in flat 
ground, and then the length, diameter and fresh weight of ginseng are recorded in time. The cultivation process of ginseng is described as follow. Seeding: through refining the cells of ginseng, combined with the clonal propagation technology, the seeds of ginseng could be obtained, and then the temperature, humidity, light intensity and ventilation should be concerned. Domestication: the ginseng seeds gradually adapt to the greenhouse environment. When the leaf and root become mature, the ginseng can be planted. Washing: the culture medium and seeds are removed from bottles, and the quality seeds and contaminated seeds should be separated. At last, the culture medium and agar should be cleaned be water. Planting: according to the alternation of season, weather and climate, the humidity and temperature should be concentrated. Harvest: the harvest of ginseng is usually conducted from late fall to early spring. Although the ginseng has stopped growing, the CO2 concentration, temperature and light still need to be ensured.

\subsection{The information collection of ecological factors}

The ecological factors of ginseng, such as temperature, humidity, $\mathrm{pH}$ and light are collected by different kinds of sensors, and then these information are transferred to cloud, and eventually farmers could inquire these ecological factors through the mobile APP and PC. The information collection collects the ecological factors of the greenhouse to the host computer through the serial port, and eventually saves them to the database, so as to make use of the control system. The data of ecological factors of ginseng from March to September are listed in Table 1. Through the information collection and analysis, the optimization of ecological factors could be selected, so as to get the optimized range of ecological factors of the growth of ginseng.

Table 1 The average values of ecological factors of ginseng from March to September

\begin{tabular}{|c|c|c|c|c|c|c|c|c|c|c|c|}
\hline Ecological factors & \multicolumn{10}{|c|}{ Values } \\
\hline Date & $\begin{array}{c}5 \\
\text { March }\end{array}$ & $\begin{array}{c}24 \\
\text { March }\end{array}$ & $\begin{array}{c}12 \\
\text { April }\end{array}$ & $\begin{array}{c}1 \\
\text { May }\end{array}$ & $\begin{array}{c}5 \\
\text { May }\end{array}$ & $\begin{array}{c}20 \\
\text { May }\end{array}$ & $\begin{array}{c}8 \\
\text { June }\end{array}$ & $\begin{array}{c}27 \\
\text { June }\end{array}$ & $\begin{array}{c}17 \\
\text { July }\end{array}$ & $\begin{array}{c}5 \\
\text { August }\end{array}$ & $\begin{array}{c}25 \\
\text { August }\end{array}$ \\
\hline Temperature $/{ }^{\circ} \mathrm{C}$ & -1 & 6 & 10 & 12 & 15 & 18 & 13 & 25 & 21 & 20 & 21 \\
\hline Humidity $/ \%$ & 61 & 66 & 72 & 82 & 83 & 88 & 92 & 91 & 83 & 76 & 69 \\
\hline Light $/ \mu \mathrm{mol} / \mathrm{m} 2 \mathrm{~s}$ & 30 & 35 & 41 & 42 & 41 & 45 & 56 & 66 & 85 & 81 & 76 \\
\hline $\mathrm{pH}$ & 5.2 & 5.5 & 6.1 & 6.5 & 6.2 & 5.7 & 5.5 & 5.4 & 5.3 & 5.2 & 5.3 \\
\hline
\end{tabular}

\subsection{The control system of ecological factors}

The control system starts the actuators every $10 \mathrm{~min}$. Under the control system, farmers could switch the working conditions of actuators, such as draught fans and pumps based on the optimization of ecological factors, which realize the reasonable regulation of parameters and actions of actuators.

\section{Summary}

To sum up, "Internet plus" has risen to national strategy. Due to the trend of combination between Internet industry and other industries, the Internet has penetrated into every aspect of our society. This paper designed a information collection and control system for ginseng ecological factors based on "Internet plus" and data analysis technology. Ginseng Farmers could utilize this system to obtain the real-time data of ecological factors, such as temperature, humidity, CO2 concentration, $\mathrm{pH}$ and light, and then some actuators could be controlled through this system as well. Case study showed that the information collection and control system based on "Internet plus" could reduce the labor intensity of farmers and promote the efficiency of ginseng planting.

\section{Acknowledgement}

(1) Nature science fund item of Jilin science and technology development plan project: Study on the monitoring technology of ginseng growth environment parameters using wireless sensor 
network(20150101099JC), Hongwei Zhu.

(2) Construction project of science and technology innovation center and the service platform of science and technology in the development plan project of Jilin provincial science and technology department, Laiwu Yin, Hongwei Zhu.

(3) Key subject cultivation project of JiLin Agricultural Science and Technology University: Research on the monitoring system of ginseng growth environment parameters based on the technology of Internet of things (2015, X097), Hongwei Zhu

\section{References}

[1] Sun Dingxin. Research on the Model of Ecological Factors of Dendrobium Huoshanness Based on "Internet Plus" [J]. Science Education, 2017, 8: 295-300.

[2] Hu Wencui. Analysis on the Development of Fresh E-commerce O2O in China [J]. China Journal of Commerce, 2016, (7): 34-35.

[3] Xie Caixiang, Suo Fengmei, Jia Guanglin, et al. Correlation between ecological factors and ginsenosides. Acta Ecologica Sinica, 2012, 31(24): 7551-7563.

[4] Wang Lili. Study on Panax and Gen-seng Information Real-time Gathering System [D]. Jilin University, 2006.

[5] Yu Haiye, Ma Chenglin, Wang Zhenhua, et al. Present Status and Analysis of Remote Control of Greenhouse Environment via Internet. Transactions of the Chinese Society of Agricultural Machinery, 2003, 34(6): 160-163.

[6] Dai Xiaohua, Xia Feng, Wang Zhi, et al. A Survey of Intelligent Information Processing in Wireless Sensor Network. Lecture Notes in Computer Science, 2005, (3794): 123-132.

[7] Astolfi. Discontinuous Control of Nonholonomic Systems. Systems \& Control Letters, 1996, 27(1): 37-45.

[8] State Pharmacopeia Committee of China. Chinese Pharmacopoeia. Beijing: Chinese Medical Science and Technology Press, 2010. 